\title{
Monday Effect in the Chinese Stock Market
}

\author{
Gerardo "Gerry" Alfonso Perez ${ }^{1}$ \\ ${ }^{1}$ University of Cambridge, UK \\ Correspondence: Gerardo "Gerry" Alfonso Perez, University of Cambridge, UK.
}

Received: July 27, 2017

Accepted: August 25, 2017

Online Published: November 30, 2017

doi:10.5430/ijfr.v9n1p1

URL: https://doi.org/10.5430/ijfr.v9n1p1

\begin{abstract}
The Monday effect is a well know effect in some countries around the world. The Monday effect is the observation that stock returns on Monday are statically significantly lower than for the rest of the days of the week. There is no obvious fundamental reason behind this occurrence and if it actually exists it might be due to human behavioral patterns. This Monday effect observation originated in the U.S. several decades ago and it has since being observed in several other countries. In this article the occurrence of the Monday effect is analyzed in the mainland China equity market. It was found that for the period from 2011 to 2016 there was no statistically significant Monday effect but interestingly there are indications of a possible Thursday effect. This concept was tested with several market indexes covering the two major mainland China stock exchanges (Shanghai and Shenzhen). These indexes covered also a broad spectrum of company sizes. The ChiNext index, which is a Nasdaq like type of index for the Chinese market, was also included. In this article it was also tested and confirmed that the returns on Chinese equities, as expected, do not follow a normal distribution.
\end{abstract}

Keywords: China, Monday, stock return

\section{Introduction}

Market anomalies could be defined as statistically significant events in the stock market that have no obvious justification by fundamentals. For instance, in principle there is no sound fundamental justification for having a weaker or stronger performance of the stock market on Monday on average than on Tuesdays or Thursdays. Said so, the stock market is influenced by investors behavior and human habits and such habits could conceivable have some effect on stock market results. In this article it is analyzed the so called Monday effect in China. The Monday effect is the concept that equity returns on Monday are, for some reason, statistically significant different from the results for the rest of the week and expected to be lower. The scope of this article is trying to determine is such anomaly occurs and if it is statistically significant rather than trying to explain the causes behind such anomaly (in the case that it is actually found). The Chinese market is a good fit for this type of analysis given the high percentage of retail investors compared to institutional investors. This could potentially cause that behavioral patterns of individual investors would have a significant impact on the overall performance of the stock market.

The Monday effect is not a new phenomenon with some articles from the late eighties, such as (Jaffe, 1989), (French, 1980), (Gondhalekar, 2003) mentioning lower returns on Mondays in the U.S. equity market. Some of these authors found that the Monday effect was particularly strong if there had been a correction in the previous days. The finding that the performance on the previous day has an impact on the Monday effect was also found in other countries such as Turkey (Cengiz, 2017) as well as several Latin American countries covered in (Rodriguez, 2012). In other regions, such as Western Europe, scholars have found mixed results in this regard with for instance (Ajayi, 2004) mentioning than in six of the eleven Western European countries analyzed there were negative Monday returns while in the rest the returns were actually positive. Critically, the difference of the returns for most of the countries analyzed by (Ajayi, 2004) were not statistically significant. This Monday effect is not constrained to the U.S. market with similar events happening in other countries such as Australia (Marrett, 2008) or the UK (Sutcliffe, 1988), (Board, 1988) but not in others such as India (Nageswari, 2011), (Aly, 2004) or Greece (Tsangarakis, 2007). So far there does not seem to be a generally accepted explanation for the Monday effect. It should be noted that in a perfectly efficient markets there should be no statistically meaningful difference between stock returns in any given day of the week. If this were the case then a trading strategy to take advantage of such phenomena could be put in place with the investors potentially obtaining higher than market average returns. It should also be noted that this is perhaps an oversimplification of the problem because it does not account for factors such as trading cost as well as liquidity concerns. Some of the 
previously mentioned authors have mentioned that the some of the results should be taken with caution. For instance, in the Egyptian case analyzed in (Aly, 2004) the authors did mentioned that only a few stock traded actively in the market and that such lack of trading liquidity in the rest of the stocks could distort the results.

There has been also an increasing literature regarding the disappearance of such effect in some markets. A good example is (Draper, 2002) covering the UK stock market and (Sullivan, 2003) covering the U.S. market. Interestingly the majority of articles postulating that the Monday effect does not exist anymore cover developed economies, primarily the U.S. and U.K. This might be simply due to those markets having existed for a much longer period of time, compared to most other countries, and having hence had enough time for such anomalies to organically disappear. There are even some articles, such as (Mehdian, 2001), showing the reversal of this Monday effect with countries such as the U.S. having stronger results on Monday than in other days of the week for some periods of time.

There are also some interesting articles covering the Chinese stock market. For instance, (Chia, 2011) analyzed some of the Greater China indexes covering Hong Kong, Taiwan and Shanghai. (Chia, 2011) did not include companies listed in the Shenzhen Stock Exchange. The Shenzhen Stock Exchange has risen in importance over the last few years and it is a key part of the mainland China equity market. The authors of (Chia, 2011) found that there is evidence of a day of the week effect in the Hong Kong and Taiwan markets but not in Shanghai. Another interesting article is (Wang, 2013). In (Wang, 2013) the authors found that, for the period from 2000 to 2010, there was a Monday effect in the mainland market. The result from (Wang, 2013) differ from the results found in this article. This discrepancy might be related to the different time periods analyzed.

Hypothesis

The basic hypothesis of this article is that there is not statistically significant Monday effect in the Chinese stock market for the five year period analyzed (from 2011 to 2016). This effect seems to be country specific with the existing literature showing different results from country to country.

\section{Method}

Daily closing values of five major mainland China equity index for the period from 2011 to 2016 were obtained from Bloomberg. The indexes included both A-shares and B-shares. A-shares are the predominant type of share in the Chinese market. The Chinese authorities have been gradually opening the A-share market to overseas investors over the last few decades. B-shares are a much smaller subset of Chinese equities and were basically an experiment to allow foreign participation in the Chinese capital market. Originally only foreigners i.e., non-Chinese entities, could purchase B-shares. As the Chinese capital markets opened up the function of B-shares has clearly decreased. Another major distinction among Chinese equities is the place of listing. Currently China has two stock exchanges, the Shanghai Stock Exchange and the Shenzhen Stock Exchange. Both exchanges are covered by the indexes analyzed. There is good consistency between those two exchanges regarding trading hours and holidays. This is not the case with Chinese exchanges outside the mainland with for instance the Hong Kong Stock Exchange having different trading hours as well as different holiday periods. This consistency of trading periods makes comparison between the performance of stocks in the Shanghai and the Shenzhen markets relatively clean.

The indexes included are: 1) the CSI 300 index that is one of the frequently used equity benchmarks for the Chinese market. The CSI 300 index is composed by the 300 largest listed companies in the mainland market and it includes A-share companies only. 2) The Shanghai Component index. The Shanghai Composite index is a broad market index and it is composed by all the A-shares and B-shares listed in Shanghai. 3) The Shenzhen Composite Index. The Shenzhen Composite Index is similar to its Shanghai counterparty and it is composed by all the A-shares and B-shares listed in the Shenzhen Stock Exchange. 4) The FTSE A50 Index is another widely used index. It includes only the 50 largest companies listed in the mainland market, regardless if they are listed in Shanghai or Shenzhen. 5) ChiNext Index is the last index analyzed. It is composed only by A-shares of new economy stocks with a tilt towards technology companies. In that regard the ChiNext is similar to a NASDAQ type of index.

The daily closing prices for the index were converted into returns and the returns grouped by day of the week, creating a time series for each day (from Monday to Friday) for each index. As usual the first stage was to determine if the data follow a normal distribution. This was tested with a Lillie test at a 5\% significance level. According to the results from these tests the stock returns, as expected, did not follow a normal distribution. Some basic initial descriptive statistics such as mean, median and standard deviation were obtained for each day for each index (Table $1)$. 
Table 1. Basic statistics for average daily returns (in percentage terms)

\begin{tabular}{|c|c|c|c|c|c|}
\hline & CSI 300 & FTSE A50 & Shanghai Com. & Shenzhen Com. & ChiNext \\
\hline \multicolumn{6}{|l|}{ Monday } \\
\hline Mean & 0.0612 & -0.0248 & -0.0080 & -0.0455 & -0.0780 \\
\hline Median & 0.2722 & 0.0887 & 0.3142 & 0.1143 & -0.1215 \\
\hline STD & 2.5483 & 1.7925 & 2.1000 & 1.8994 & 1.9513 \\
\hline \multicolumn{6}{|l|}{ Tuesday } \\
\hline Mean & 0.1123 & 0.0562 & 0.1150 & 0.0666 & 0.0611 \\
\hline Median & 0.1079 & 0.1025 & 0.2418 & 0.0654 & 0.0707 \\
\hline STD & 2.1062 & 1.4250 & 1.7335 & 1.5010 & 1.4944 \\
\hline \multicolumn{6}{|c|}{ Wednesday } \\
\hline Mean & 0.2163 & 0.0932 & 0.1899 & 0.0921 & 0.0612 \\
\hline Median & 0.2382 & 0.0282 & 0.1983 & 0.0071 & -0.0350 \\
\hline STD & 2.0291 & 1.2907 & 1.5933 & 1.3982 & 1.3667 \\
\hline \multicolumn{6}{|c|}{ Thursday } \\
\hline Mean & -0.1961 & -0.1565 & -0.1760 & -0.1813 & -0.1321 \\
\hline Median & -0.1243 & -0.1574 & -0.1086 & -0.2360 & -0.2340 \\
\hline STD & 2.0389 & 1.4806 & 1.6686 & 1.5851 & 1.5889 \\
\hline \multicolumn{6}{|l|}{ Friday } \\
\hline Mean & 0.1081 & 0.1209 & 0.0994 & 0.1490 & 0.1760 \\
\hline Median & -0.0376 & 0.1275 & 0.0685 & 0.1411 & 0.1953 \\
\hline STD & 1.9208 & 1.3746 & 1.5892 & 1.4481 & 1.3988 \\
\hline
\end{tabular}

Then a Wilcoxon test was performed to compare the returns obtained by each of the five indexes on Monday with the returns obtained by those indexes during all the other days of the weeks (Table 2). The fundamental hypothesis is that the returns on Monday are statistically equal while the alternative assumption is that they are not. For completeness purposes the returns of the indexes were not only compared to themselves but also with the other indexes. Strictly speaking the Monday effect only encompasses comparisons of an index with itself for different days of the week as the returns of other indexes can be driven by different factors. Nevertheless, it seemed interesting comparing the performance between indexes.

\section{Results}

As expected the daily returns of the five indexes analyzed describing the performance of Chinese stocks did not follow a normal distribution. The returns of the five indexes on Monday were compared with the returns of the index for the rest of the days of the week using a Wilcoxon test, see table 2. The returns for the CSI 300 for all the days of the week can be seen in figure 1. The returns for the other indexes are shown in the appendix. Interestingly the only day of the week, for the period analyzed, that had negative means and median for all the indexes analyzed was Thursday, rather than Monday. The mean and median of the returns for most indexes on Monday were negative for the majority of the indexes with the exception of the CSI 300 Index.

When a formal Wilcoxon test is performed the results indicate that, at a 5\% significance level, the Monday returns of the indexes were statistically different, when compared to the returns of the same index, for all the indexes on Thursday, with the exception of the A50 Index. There was also one index with statistically different returns on Friday when compared to the returns on Monday (the A50 index). The results seem to support the idea that there is no Monday effect but there are indications that there might be a Thursday effect. There is no obvious explanation explaining why the returns on the market on Thursday should be lower than during the rest of the days of the week. It might be related to a tendency by investors to decrease exposure to the stock market before the end of the week but there is no obvious statistical approach to test the validity of such hypothesis. 
It is also interesting (Table 1) that Thursday is not only the day of the week with more discrepancies in performance of the indexes compared to their own performance on Monday but also the day of the week with more discrepancies of performance among different indexes. In this regard the performance of the Shenzhen Composite and the ChiNext index deserve particularly attention. On Thursday the performances of those two indexes were statistically meaningfully different from the performance of all other index, including themselves, on Monday. This behavior seems rather different from the one observed on all the other days of the week.
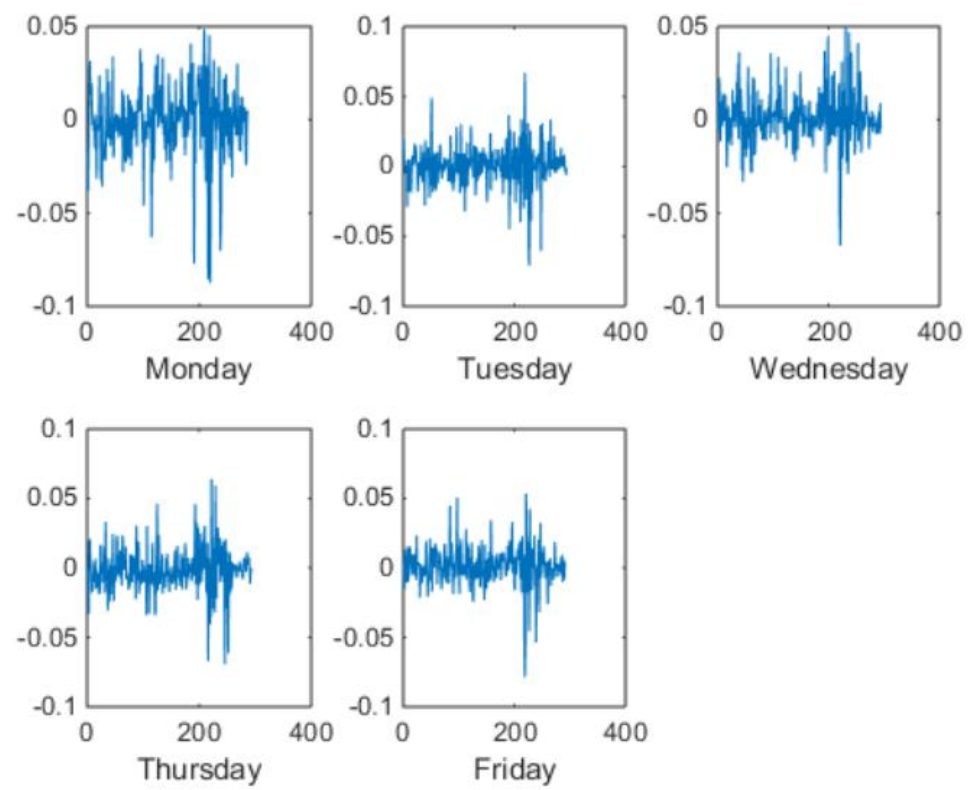

Figure 1. CSI 300 returns per day of the week

\section{Discussion}

The results seem to suggest that there is no significant Monday effect in the Mainland Stock market while there are some indications of a Thursday effect. There is no obvious fundamental reason for the apparent weaker performance of the stock market on Thursdays and it might be related to merely behavioral characteristics predominant in the investor base. The investor base in China is mostly retail and such behavioral patterns could potentially have a significant influence in the market. It would be interesting to see if there is a change in this dynamics as the Chinese market gradually opens up and becomes more integrated with the global market. 
Table 2. Wilcoxon test per day of the week

\begin{tabular}{|c|c|c|c|c|c|c|c|c|c|c|}
\hline & \multicolumn{2}{|c|}{ CSI300 (Mo) } & \multicolumn{2}{|c|}{ FTSE A50 (Mo) } & \multicolumn{2}{|l|}{$\begin{array}{l}\text { Shanghai } \\
\text { Com.(Mo) }\end{array}$} & \multicolumn{2}{|l|}{$\begin{array}{l}\text { Shenzhen } \\
\text { Com.(Mo) }\end{array}$} & \multicolumn{2}{|l|}{ ChiNext (Mo) } \\
\hline & $\mathbf{p}$ & $\mathbf{h}$ & $\mathbf{p}$ & $\mathbf{h}$ & $\mathbf{p}$ & $\mathbf{h}$ & $\mathbf{p}$ & h & $\mathbf{p}$ & $\mathbf{h}$ \\
\hline CSI00 (Tu) & 0.7498 & 0 & 0.1164 & 0 & 0.9887 & 0 & 0.2265 & 0 & 0.1964 & 0 \\
\hline FTSE A50 (Tu) & 0.8605 & 0 & 0.1630 & 0 & 0.8926 & 0 & 0.1788 & 0 & 0.1604 & 0 \\
\hline Shanghai Com.(Tu) & 0.6770 & 0 & 0.0790 & 0 & 0.9311 & 0 & 0.1848 & 0 & 0.2000 & 0 \\
\hline Shenzhen Com.(Tu) & 0.2028 & 0 & 0.0214 & 1 & 0.2906 & 0 & 0.7229 & 0 & 0.5036 & 0 \\
\hline ChiNext (Tue) & 0.4187 & 0 & 0.1087 & 0 & 0.5266 & 0 & 0.7865 & 0 & 0.5128 & 0 \\
\hline CSI00 (We) & 0.9563 & 0 & 0.1903 & 0 & 0.7702 & 0 & 0.1661 & 0 & 0.1685 & 0 \\
\hline FTSE A50 (We) & 0.7524 & 0 & 0.3604 & 0 & 0.5131 & 0 & 0.0774 & 0 & 0.0959 & 0 \\
\hline Shanghai Com.(We) & 0.8738 & 0 & 0.1283 & 0 & 0.8754 & 0 & 0.1564 & 0 & 0.1756 & 0 \\
\hline Shenzhen Com.(We) & 0.1621 & 0 & 0.0145 & 1 & 0.2524 & 0 & 0.9035 & 0 & 0.6644 & 0 \\
\hline ChiNext (We) & 0.1439 & 0 & 0.0343 & 1 & 0.2186 & 0 & 0.7683 & 0 & 0.9118 & 0 \\
\hline CSI00 (Th) & 0.0239 & 1 & 0.2279 & 0 & 0.0077 & 1 & 0.0013 & 1 & 0.0031 & 1 \\
\hline FTSE A50 (Th) & 0.0274 & 1 & 0.2747 & 0 & 0.0075 & 1 & 0.0012 & 1 & 0.0035 & 1 \\
\hline Shanghai Com.(Th) & 0.0655 & 0 & 0.4953 & 0 & 0.0254 & 1 & 0.0022 & 1 & 0.0049 & 1 \\
\hline Shenzhen Com.(Th) & 0.1827 & 0 & 0.6535 & 0 & 0.0997 & 0 & 0.0094 & 1 & 0.0111 & 1 \\
\hline ChiNext (Th) & 0.2266 & 0 & 0.5777 & 0 & 0.1406 & 0 & 0.0290 & 1 & 0.0182 & 1 \\
\hline CSI00 (Fr) & 0.2757 & 0 & 0.0182 & 1 & 0.4112 & 0 & 0.5411 & 0 & 0.4464 & 0 \\
\hline FTSE A50 (Fr) & 0.2329 & 0 & 0.0124 & 1 & 0.3580 & 0 & 0.5723 & 0 & 0.5134 & 0 \\
\hline Shanghai Com.(Fr) & 0.3468 & 0 & 0.0248 & 1 & 0.5035 & 0 & 0.4004 & 0 & 0.3362 & 0 \\
\hline Shenzhen Com.(Fr) & 0.4195 & 0 & 0.0620 & 0 & 0.6321 & 0 & 0.5006 & 0 & 0.3255 & 0 \\
\hline ChiNext (Fr) & 0.5963 & 0 & 0.1864 & 0 & 0.7788 & 0 & 0.6068 & 0 & 0.4027 & 0 \\
\hline
\end{tabular}

\section{References}

Aly Hassan, \& Mehdian Seyed. (2004). An analysis of day-of-the week effect in the Egyptian stock market. International journal of business, 9(3).

Board J.L., \& Sutcliffe C.M. (1988). The weekend effect in the UK stock market returns. Journal of business finance \& accounting, 15(2). https://doi.org/10.1111/j.1468-5957.1988.tb00130.x

Cengiz Hulya, Bilen Omer, Hakan Ali, \& Damgacy Gulizar. (2015). Stock market anomalies: the day of the week effects, evidence from Borsa Istanbul. Journal of global entrepreneurship research, 7(4). https://doi.org/10.1186/s40497-017-0062-6

Chia Ricky, Liew Venus, \& Wafa Syed. (2011). Day of the week effect: evidence from the Chinese stock markets. Journal of international economic Review, 3.

Draper Paul, \& Krishna Paudyal. (2002). Explaining Monday returns. The journal of financial research, 2002. https://doi.org/10.1111/1475-6803.00034

French Kenneth. (1980). Stocks returns and the weekend effect. Journal of financial economics, 8(1). https://doi.org/10.1016/0304-405X(80)90021-5

Jaffe Jeffrey. (1989). A twist on the Monday effect in stock prices: Evidence from the U.S and foreign stock markets. Journal of Banking and Finance, 13(4-5). https://doi.org/10.1016/0378-4266(89)90035-6

Marrett George. (2008). The day of the week effect in the Australian stock market: An empirical note on the market, industry and small cap effect. International journal of business and management, 2.

Mehdian Seyed, \& Perry Mark. (2001). The reversal of the Monday effect: New evidence from US equity markets. 
Journal of business finance and accounting, 28(7). https://doi.org/10.1111/1468-5957.00404

P. Nageswari, M. Selvam \& J. Gayathri. (2011). Analysis of Monday Effect in Indian Stock Market. Research Journal of Business Management, 5. 170-177. https://doi.org/10.3923/rjbm.2011.170.177

Sullivan Joe, \& Liano Kartono. (2003). Market breadth and the Monday seasonal in stock returns. Quarterly Journal of Business and Economics, 42(3).

Sutcliffe C, \& Board, L. (1988). The weekend effect in the UK stock market returns. Journal of business finance and accounting, 15. https://doi.org/10.1111/j.1468-5957.1988.tb00130.x

Tsangarakis Nickolaos. (2007). The day of the week effect in the Athens Stock Exchange. Applied financial economics, 17(17). https://doi.org/10.1080/09603100600675540

Wang Jaw-Kai, \& Ojiako Udechukukwu. (2013). Calendar effects of the Chinese stock market. International journal of business and emerging markets, 5(1). https://doi.org/10.1504/IJBEM.2013.050742

Werner Kristjanpoller Rodriguez. (2012) Day of the week effect in Latin American stock markets. Revista de analisis economico, 22(1). https://doi.org/10.4067/S0718-88702012000100004

Appendix
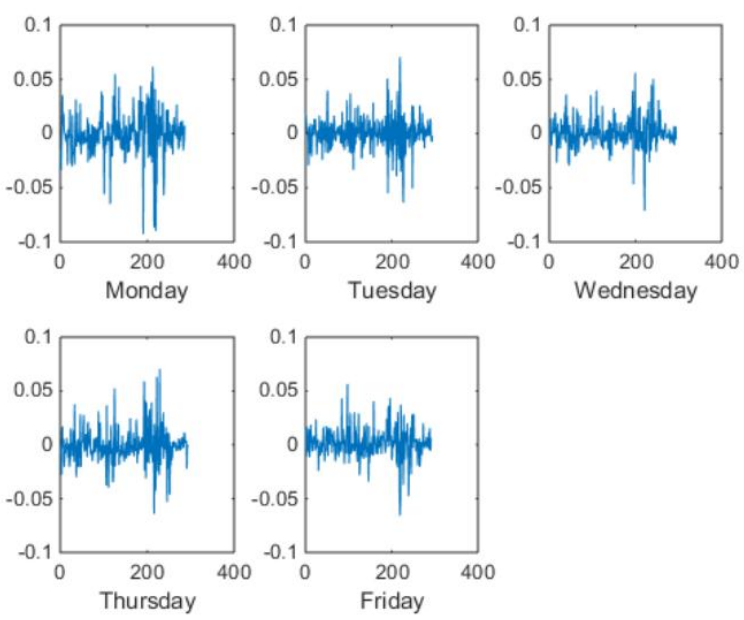

Figure 2. A50 returns per day of the week
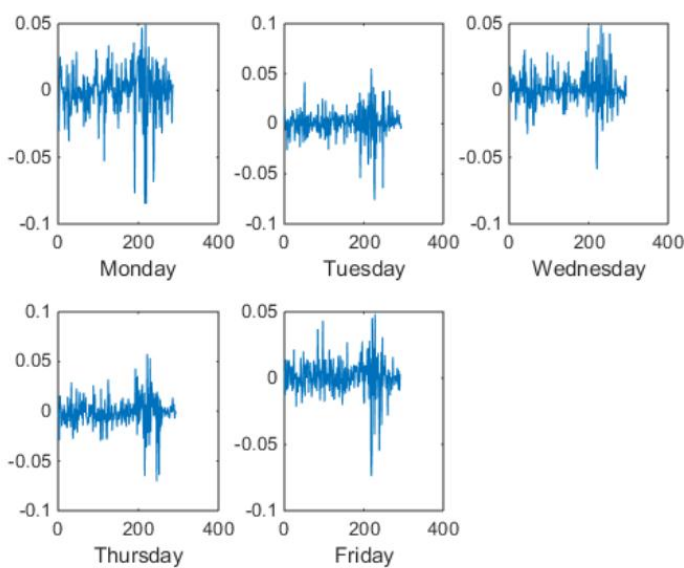

Figure 3. Shanghai Comp. returns per day of the week 

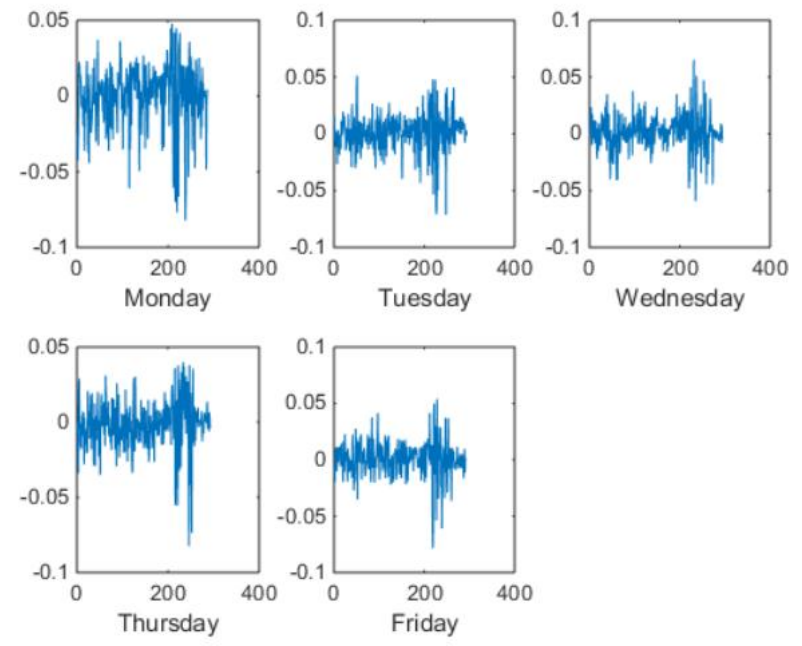

Figure 4. Shenzhen Comp. returns per day of the week
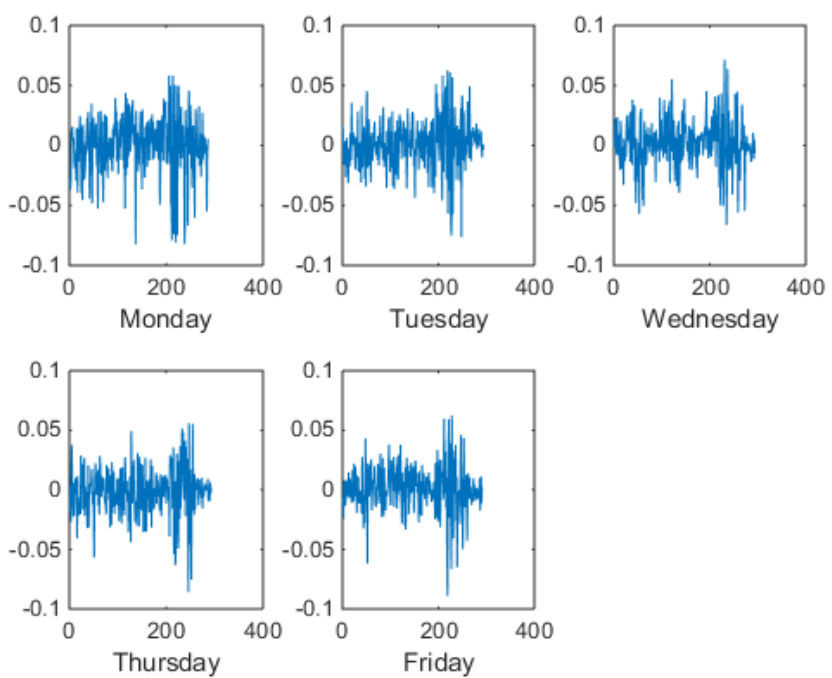

Figure 5. ChiNext returns per day of the week 